\title{
Erratum: Increase in the glide path diameter improves the centering ability of F6 Skytaper
}

In the article titled "Increase in the glyde path diameter improves the centering ability of F6 Skytaper," published on pages 89-93, Issue 1, Volume 12 in European Journal of Dentistry, ${ }^{[1]}$ the term "glide" was misspelled as "glyde" in the entire article.

The correct article title should be read as "Increase in the glide path diameter improves the centering ability of F6 Skytaper."

\section{Acknowledgment}

The authors would like to thank Dr. Ravi Sv and Dr. Swapna Honwad of Department of Conservative Dentistry and Endodontics, KMCT Dental College, Calicut, 673602 Kerala, India for their comments.

\section{REFERENCE}

1. Troiano G, Dioguardi M, Cocco A, Zhurakivska K, Ciavarella D, Muzio LL. Increase in the Glide path diameter improves the centering ability of F6 Skytaper. Eur J Dent 2018;12:89-93.

DOI: $10.4103 / 1305-7456.237851$ 